\title{
Premature Failure and its Prevention in Flexural Beams Retrofitted by GFRP Fibers
}

\author{
Amir Reza Eskenati ${ }^{1}$, Hamid Varasteh Pour ${ }^{2}$ \\ ${ }^{1}$ Department of Civil Engineering, Neyshabur Branch, Islamic Azad University, Iran \\ 2Institute for Energy and Hydro Technology Power Industry, Mashhad, Iran \\ corresponding author: aeskenaty@yahoo.com
}

\begin{abstract}
Nowadays, retrofitting reinforced concrete with FRP fibers is regarded as a globally significant issue. In reinforced concrete beam, the shear failure mode is more dangerous than flexural failure mode. Because this thin and sudden mode occurs without any pre-warning, diagonal shear cracks are wider than flexural cracks and preventing their expansion is rather difficult. In the present study, the concrete beams are retrofitted with GFRP fibers through a common method. Then, the beams have fourpoint bending test until the premature failure occurs. This phenomenon is relatively prevented through retrofitting along the shear. The failure of beams are examined here.
\end{abstract}

Key words: FRP, flexural retrofitting, GFRP, reinforced concrete beam

\section{Introduction}

Basically, the reinforced concrete beams fail in two modes: flexural and shear. It is evident that in contrast with flexural failure mode which is a ductile one, the shear failure mode of concrete beam is sudden and with brittle nature. In addition, its time of occurrence is not easily predictable and shear failure does not present much warning before failure. Therefore, shear failure is more dangerous than flexural failure. As a result, the reinforced concrete beams should be designed in way that they can attain their total flexural capacity and under maximum loads, these beams must represent a ductile flexural failure mode.

Most of the concrete structures face problems in dealing with shear due to numerous reasons which include mistake in design computations, incorrect details of shear bar, and errors during construction and lack of their correction, changes in application of a structure with shift from lower service load to higher one, and reduction of shear bar area as a result of corrosion under environmental conditions. As a result, the option of retrofitting technique is a highly proper one for structures which need replacement of structures.

There are different techniques for retrofitting concrete beams against shear such as application of polymer fibers and composites, concrete jacks, external pre-stressing and usage of steel plates. Basically, the application of FRP fibers is an effective and simple method for increasing the shear and flexural strength of beams. In the present study, by FRP, the beams flexural retrofitted and three beams in shear mode is also retrofitted.

\section{Literature}

Many researchers in the inside and outside of country in the many efforts in the field of theoretical work focused on the behavior of tension in the bottom of the page. However, laboratory studies 
show that preterm rupture can be started with the opening of bending and shear cracks. Pawłowskia and Szumigałaa [6], investigate the Flexural behavior of full-scale basalt FRP RC beams in two methods: experimental and numerical studies. In this study, the reinforcement ratio has a significant effect on the flexural behavior of BFRP RC beams, and an increase in the reinforcement ratio results in an increase in the ultimate loads and in the stiffness of the beams [6].

Irshidat et. al [4] investigate the effect of carbon nanotubes on strengthening of RC beams retrofitted with carbon fiber/epoxy composites in experimental method. In this study, he concluded: modification of epoxy resin with CNTs did not change the crack patterns and failure mode of retrofitted beams but delayed the propagation of carbon fiber sheet debonding and modification of epoxy resin with CNTs (B-CNT specimens) slightly improved the beams ultimate load by 5\%, but significantly enhanced its stiffness and toughness by $35 \%$ and $28 \%$, respectively, compared to B-NE specimens.[4]

In order to compare the effects of wrapping as complete or interrupted wrapping with various intervals, carried out tests on samples with a diameter of $150 \mathrm{~mm}$ and a height of $300 \mathrm{~mm}$ cylindrical [1]. These tests were performed for CFRP bars. Results of this study show that despite the low impact of the interrupted braids in increasing freight, the effect of the braids in the form of samples is very significant [1]. In this study, to increase bending and freight capacity in easier and more efficient way to use in out of laboratory environment.

\section{Model Formulation}

\subsection{Failure Mechanism and Failure Mode}

The shear and flexural failures are the most significant failure modes for non-retrofitted beams. The flexural failure is preferred to shear failure due to brittleness of the latter because in regard to soft failure, it is possible to redistribute stress. This could act a warning for the user. While the brittle and sudden failure might lead to catastrophe due to lack of pre-warning; the beam ductility after flexural retrofitting with the help of external FRP layers is much lower than non-retrofitting scenario. However, this mode of failure is softer than shear failure. Therefore, a retrofitted beam should have sufficient shear capacity. When a reinforced concrete beam has weakness in its shear or the shear capacity of the beam is less than its flexural capacity, the shear retrofitting must be taken into account after flexural retrofitting. It should be noted here that measuring shear capacity of the retrofitted beam is highly significant. At times, shear retrofitting plays a key role in retrofitting strategy of reinforced concrete buildings. However, there are few traditional methods for shear retrofitting of beams. Recently, the application of FRP strips has been increasingly taken into consideration. Along the other outstanding requirement of FRPs such as resistance against corrosion and strength of wing in comparison to weight, the flexibility of FRPs to fit with other shapes and corners is useful for retrofitting. The studies on shear retrofitting started from 1990 onwards. The connection of FRP materials to tensile zone of the concrete in a way that their fibers are along the longitudinal direction of a flexural element increases the flexural strength of the element.

The flexural strength of a retrofitted section depends on its failure mode. The following modes of flexural failure are examined for a section:

1- Crushing of compressive concrete before flow of steel

2- Failure of FRP layers after flow of tensile steel

3- Crushing of compressive concrete after flow of tensile steel

4- Disengagement of FRP from its underlying concrete layer

5- Separation of concrete cover in shear and tensile levels 
In some cases, it is initially difficult to detect the type of failure. Therefore, a failure mode is initially presumed; and after analysis, it is examined whether this mode occurs. If the initial hypothesis is correct, another failure mode presumed and the analysis will be repeated.

\subsection{Flexural Failure}

If the end of FRP sheet is properly restrained, the final flexural capacity of the beam is obtained along with flexural failure of the sheet or crushing of compressive concrete. This is very similar to classic flexural failure mode of reinforced concrete beam and due to brittleness, the behavior of FRP sheet is relatively different. The failure of FRP sheet is accompanied by flow of steel bars. If the steel bars are very distant from tensile aspect (i.e. close to the neutral fiber), they may not flow. A beam which collapses due to crushing of the concrete, the reason for it might be high amount of FRP and brittle crushing of the piece. In addition, with proper terminal restraining, one can prevent premature debonding failure [7]

In Figure 1, the comparison of the beam in flexural mode is provide while in Figure 2, the flexural failure modes are presented.

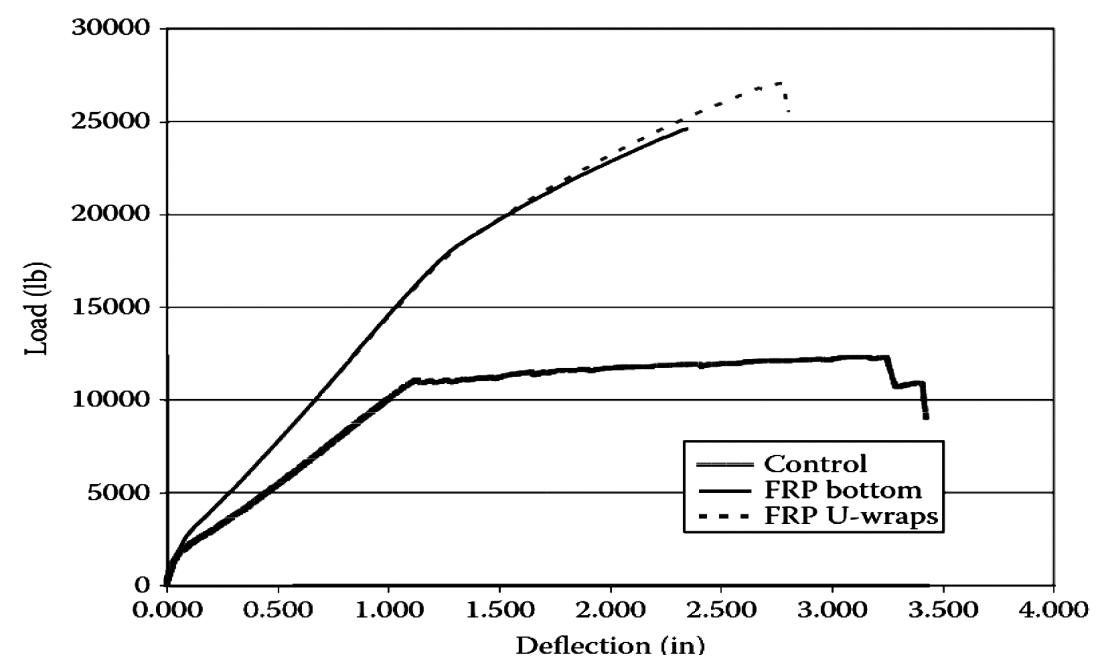

Figure 1. Comparison of FRP-retrofitted beam in two modes with control beam

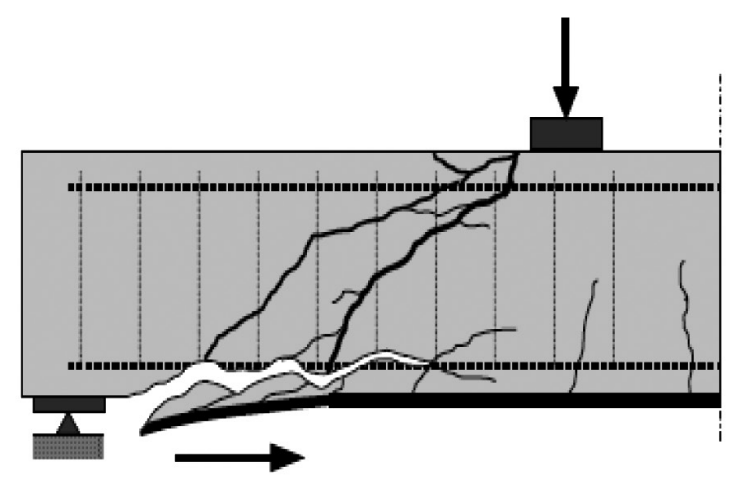

(a) Shear failure with concrete cover debonding

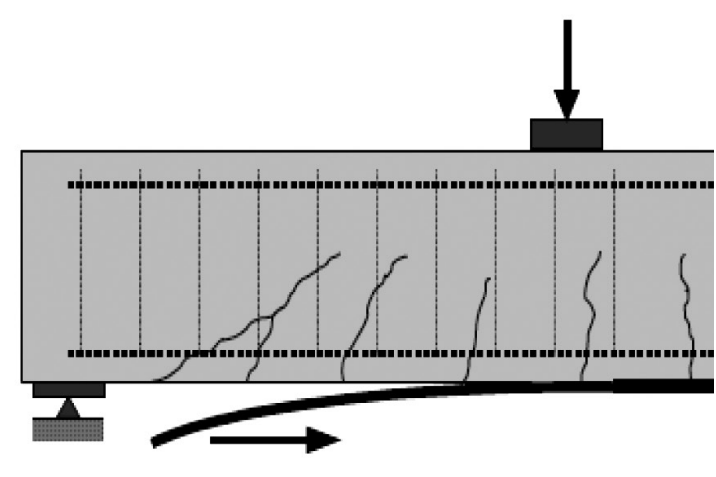

(b) FRP debonding from plate end 


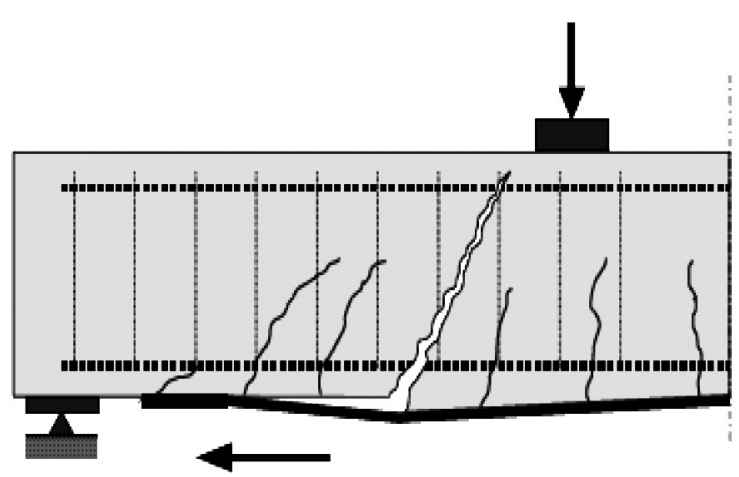

(c) FRP debonding from flexure-shear crack

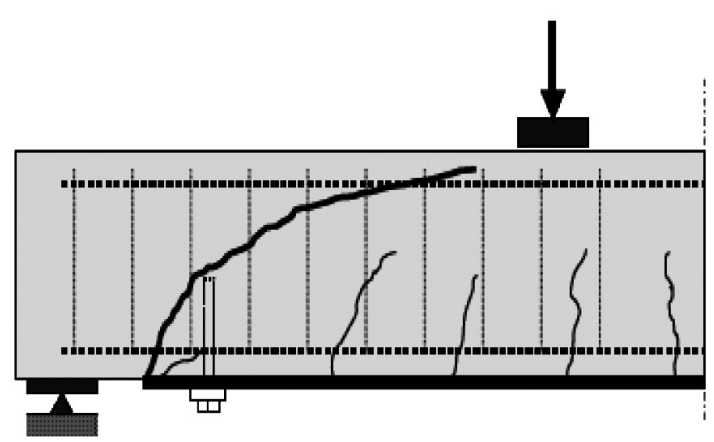

(e) Plate end shear failure

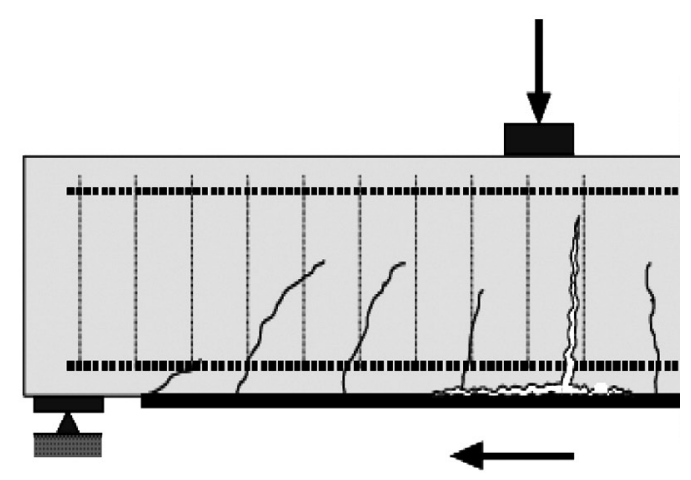

(d) FRP debonding from flexural crack

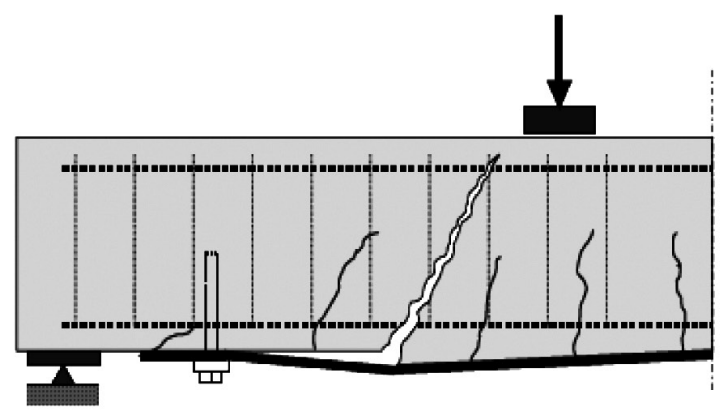

(f) Shear failure and debonding

Figure 2. (a) Shear failure with concrete cover debonding, (b) FRP debonding from plate end, (c) FRP debonding from flexure-shear crack, (d) FRP debonding from flexural crack, (e) plate end shear failure, and (f) shear failure and debonding [3]

\subsection{Shear Failure}

The typical reinforced concrete beams are designed for failure in flexural mode which is a softer mode than shear failure mode which is more brittle. Considering this issue is necessary that shear failure might occur due to effect of flexural mode retrofitting. In some cases, flexural and shear retrofitting are simultaneously done to assure that the flexural failure occurs before shear failure [2]. The following figure shows an instance of shear failure.

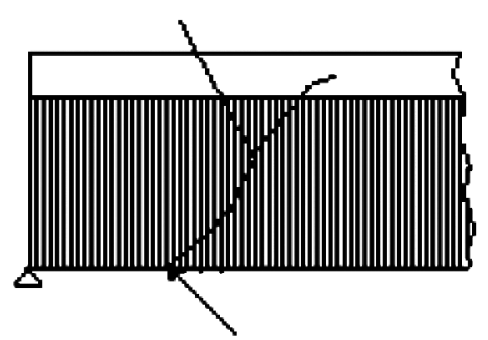

[1] FRP rupture starts here

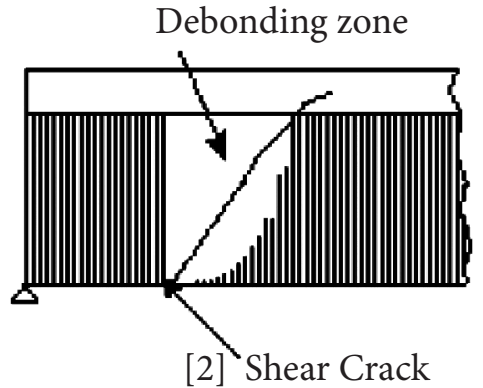

[2] Shear Crack

Figure 3. (1) Tensile shear with FRP rupture [1] (2) and shear failure due to FRP debonding [5] 


\section{Methods}

The concrete beams are retrofitted through glass fibers that are classified in the following manner.

\section{First Group}

B1: Control sample tested without retrofitting

B2: A sample retrofitted through common method and an underlying GFRP layer

B3: A sample retrofitted through common method and two underlying GFRP layers

B4: A sample retrofitted through common method and three underlying GFRP layers

\section{Second Group:}

B5:A sample retrofitted through common method and a retrofitting layer, continuation of retrofitting with $5 \mathrm{~mm}$ above concrete cover

B6: A sample retrofitted through common method and two retrofitting layers, continuation of retrofitting for $5 \mathrm{~mm}$ above concrete cover

B7: A sample retrofitted through common method and three retrofitting layers, continuation of retrofitting for $5 \mathrm{~mm}$ above concrete cover

\section{Results and Discussion}

The test is done in a way that all test beams have four-point flexural test and they have two joint heads. Loading is applied as load change control with a rate of $10 \mathrm{~kg} / \mathrm{sec}$. The load-displacement diagram is drawn through 200-ton jack device. For each beam, we observe different failure as shown in the following figures.

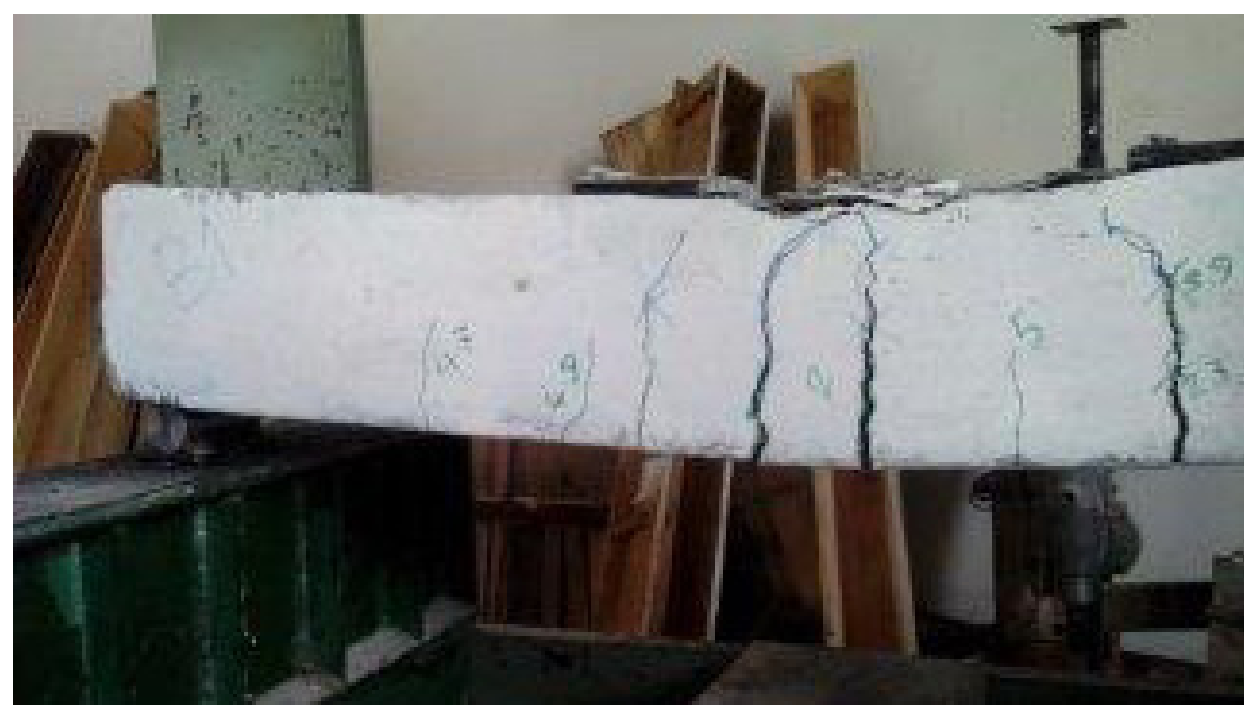

Figure 4. Type of B1 beam failure after load application 


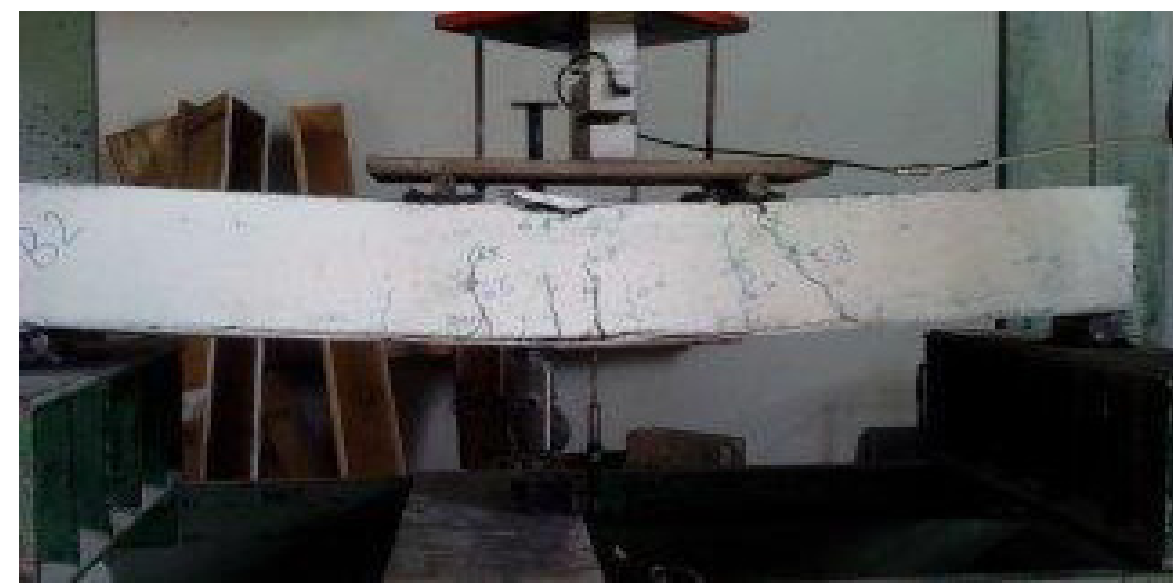

Figure 5. Type of B2 beam failure after load application

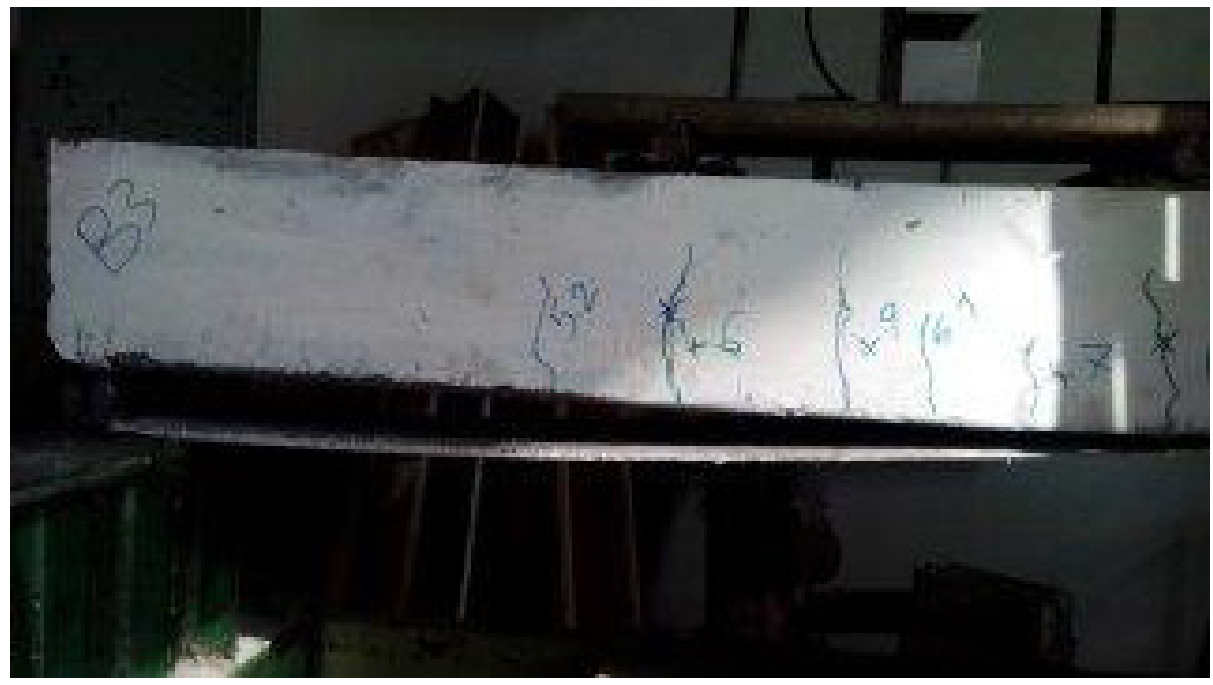

Figure 6. Type of B3 beam failure after load application

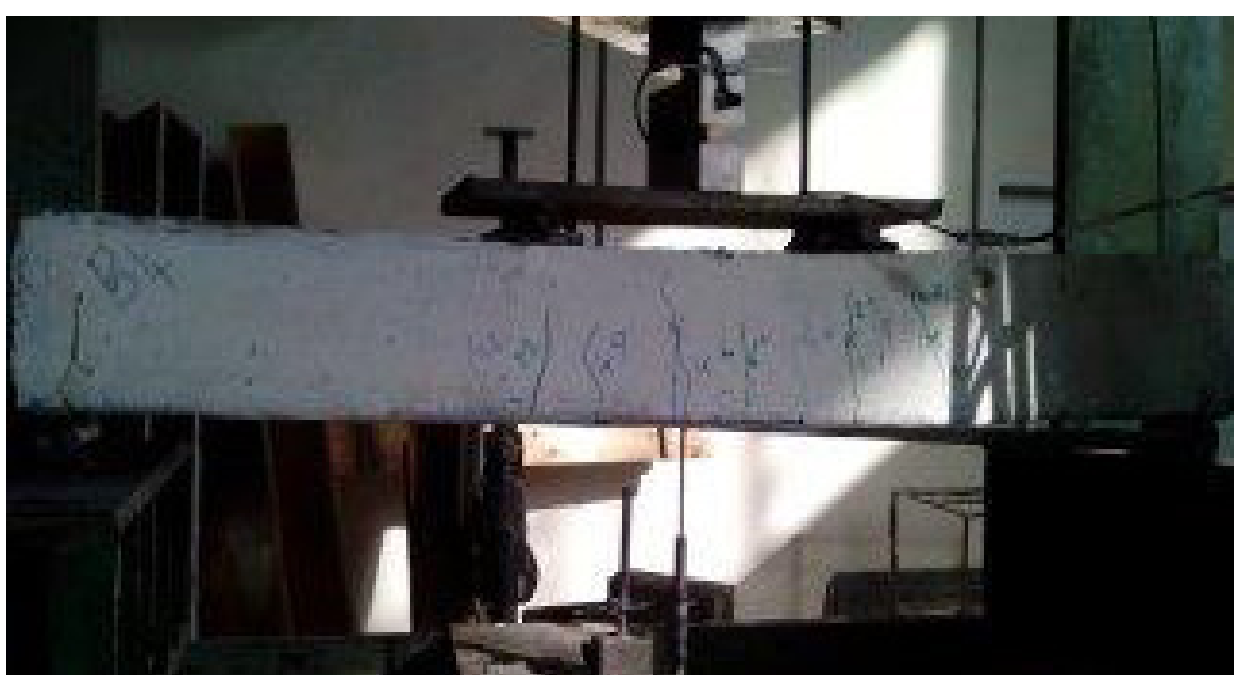

Figure 7. Type of B4 beam failure after load application 
18 Premature Failure and its Prevention in Flexural Beams Retrofitted by GFRP Fibers

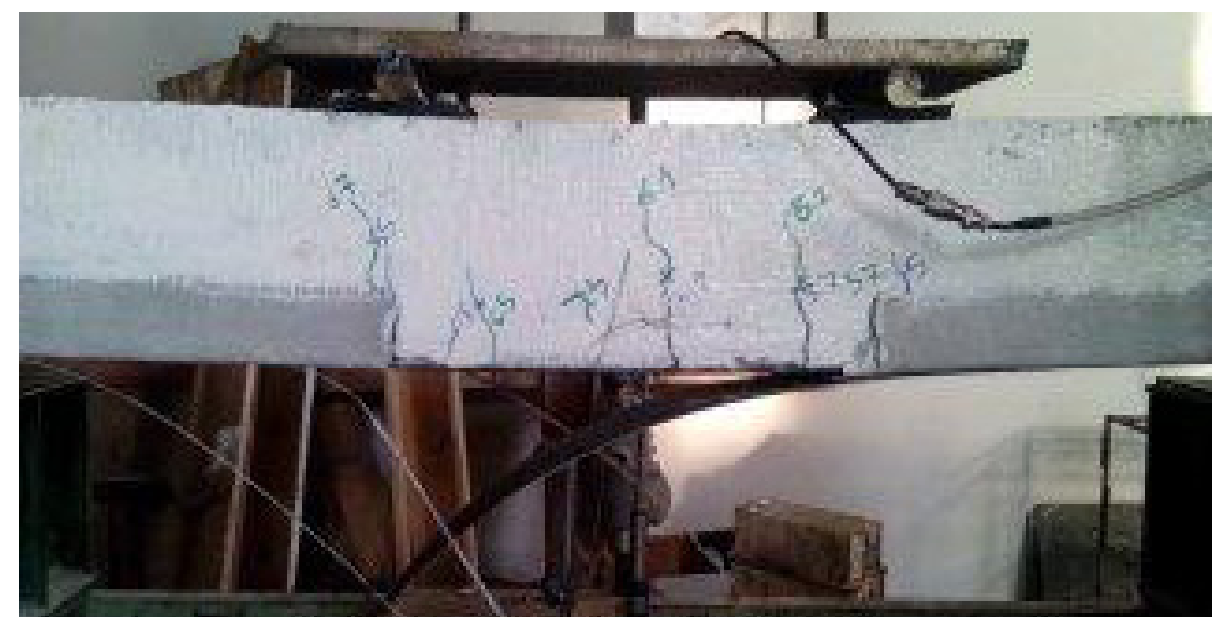

Figure 8. Type of B5 beam failure after load application

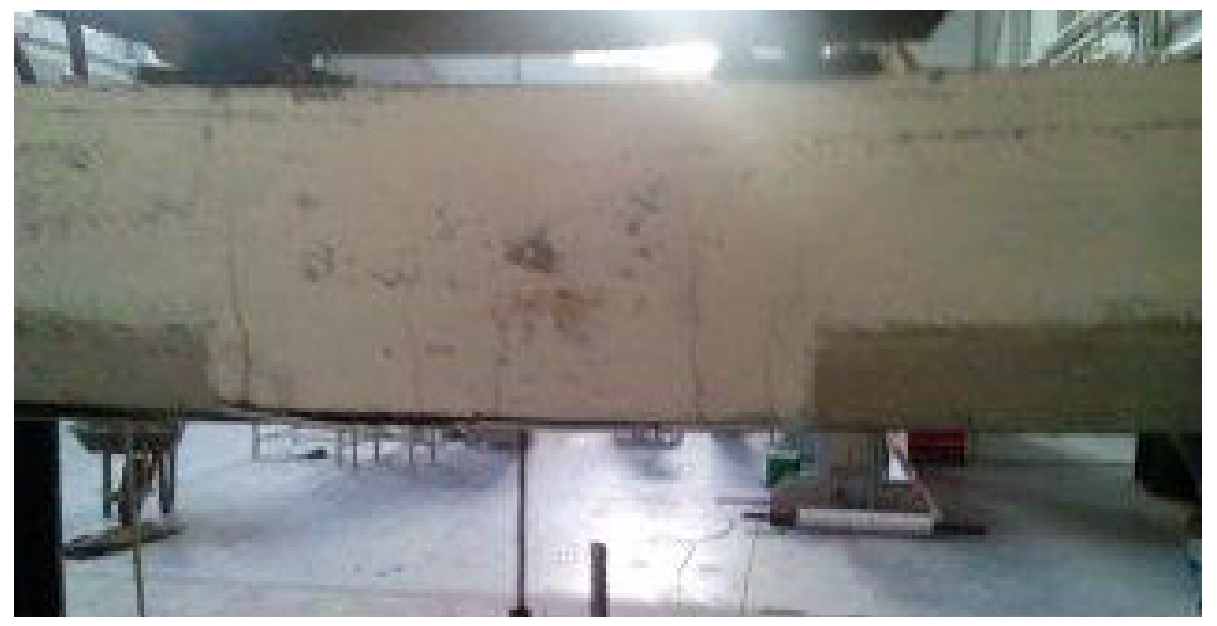

Figure 9. Type of B6 beam failure after load application

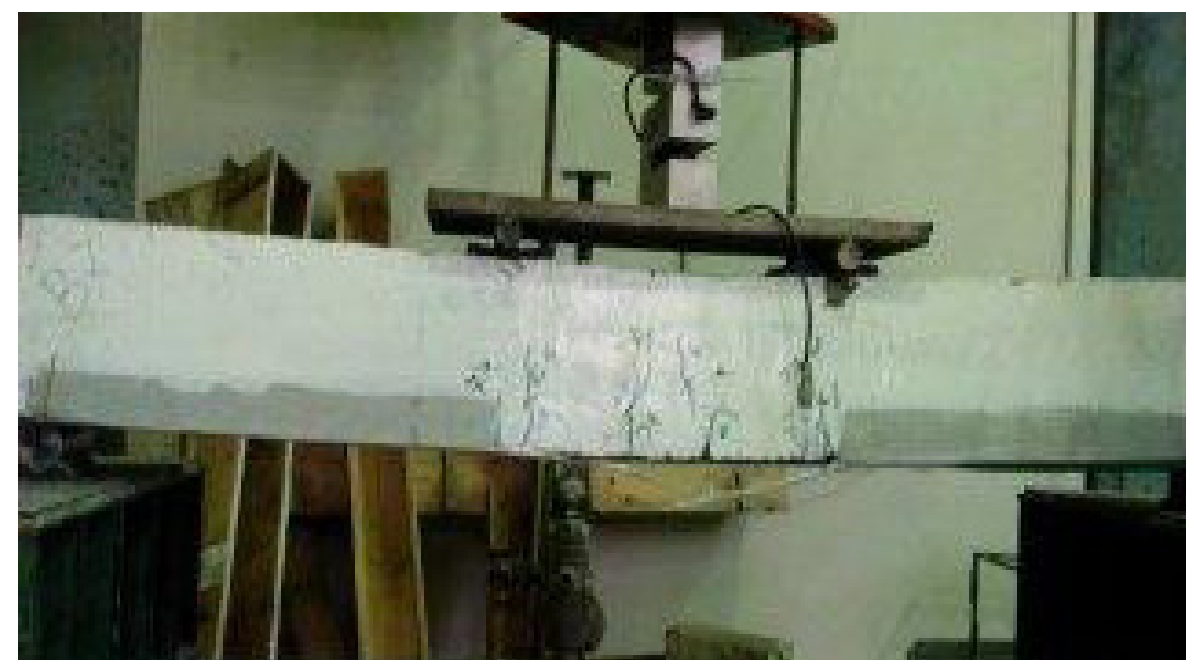

Figure 10. Type of B7 beam failure after load application 
The type of failure for the beams after loading is shown in the following table.

Table 1. The Comparison of the Results of the Samples

\begin{tabular}{|c|c|}
\hline Number of Sample & Type of Failure \\
\hline B1 & Flexural \\
\hline B2 & Shear and Premature Failure \\
\hline B3 & Shear and Premature Failure \\
\hline B4 & Shear and Premature Failure \\
\hline B5 & Shear and Premature Failure \\
\hline B6 & Shear and Failure in Concrete Cover \\
\hline B7 & Shear and Failure in Concrete Cover \\
\hline
\end{tabular}

\section{Conclusion}

The application of GFRP layer increases the flexural capacity of the beam but it is not cost-effective due to its prices. As expected, the premature failure leads to a state in which the section does not get to flexural capacity after retrofitting. The application of GFRP layers for retrofitting beams significantly reduces ductility. This issue is clearly observed in a beam with 1 layer and cover retrofitting.

Acknowledgment: The author appreciates the contributions of his father and Mat Beton Paya Company as the main financial sponsor of the present study.

\section{References}

[1] Barros J and Ferreira D (2008), Assessing the Efficiency of CFRP Discrete Confinement ystems for Concrete Cylinders. Journal Composite Construction, 10 : 134-148.

[2] Blashchko M, Niedermeier R and Zilch, K (1998), Bond failure modes of flexural members strengthened with FRP. Second International Conference on Composites in Infrastructure, 1 : 315-327

[3] Gunes O (2004), A fracture-based approach to understanding debonding in FRP bonded structural members, Department of Civil and Environmental Engineering, Massachusetts Institute of Technology, USA.

[4] Irshidat MR, Al-Saleh MH and Almashagbeh H (2015), Effect of carbon nanotubes on strengthening of RC beams retrofitted with carbon fiber/epoxy composites. Materials and Design, Elsevier, 89 : 225-234.

[5] Khalifa A and Nanni A (2002), Rehabilitation of rectangular simply supported RC beams with shear deficiencies using CFRP composites. Construction and Building Materials, Elsevier, 16 : $135-146$.

[6] Pawłowskia D and Szumigałaa M (2015), Flexural behaviour of full-scale basalt FRP RC beams -experimental and numerical studies. Procedia Engineering, Elsevier, 108 : 518-525.

[7] Teng JG, Chen JF, Smith ST and lam L (2002), FRP Strengthened RC Structures. Wiley. New Jersey, USA. 